\title{
Amoxicillin Crystalluria: A Rare Side-Effect of a Commonly Prescribed Antibiotic
}

\author{
$\underline{\text { Joana Couto }}^{1}$, Luis Pontes dos Santos ${ }^{1}$, Joana Carlos Alves ${ }^{1}$, Raquel López ${ }^{1}$, Cristina Maldonado ${ }^{2}$ \\ ${ }^{1}$ Department of Internal Medicine 1, Unidade Local de Saúde do Alto Minho, EPE, Portugal \\ ${ }^{2}$ Laboratory Department, Unidade Local de Saúde do Alto Minho, EPE, Portugal
}

Received: $11 / 09 / 2017$

Accepted: 23/09/2017

Published: $23 / 10 / 2017$

How to cite this article: Couto J, Pontes dos Santos L, Alves J, Lòpez R, Maldonad C. Amoxicillin crystalluria: a rare side-effect of a commonly prescribed antibiotic. EJCRIM 2017;4: doi:10.12890/2017_000736

Conflicts of Interests: The Authors declare that there are no competing interests.

This article is licensed under a Commons Attribution Non-Commercial 4.0 License

\section{ABSTRACT}

Although crystalluria is a frequent finding in the routine examination of urine, amoxicillin crystalluria is a rare event whose incidence remains unknown. Crystalluria caused by amoxicillin is very uncommon and may be asymptomatic or have severe renal implications. The authors describe the case of an 87-year-old female patient who presented with massive amoxicillin crystalluria due to poor hydration, low urinary $\mathrm{pH}$ and high intravenous amoxicillin dosage.

\section{LEARNING POINTS}

- Amoxicillin crystalluria is a rare event.

- It can range from a transient asymptomatic crystalluria without renal damage to major haematuria or acute renal failure.

- We should be aware of this complication because high intravenous doses of amoxicillin are frequently prescribed and measures can be adopted to prevent this complication.

\section{KEYWORDS}

Crystalluria, amoxicillin, 'shock wheat' crystals, 'broom like' crystals

\section{INTRODUCTION}

Crystalluria is a frequent finding in the routine examination of sediments in urine. It was shown that crystalluria was present in $8.2 \%$ of almost 10,000 regular urine samples. In most cases, the crystals are composed of calcium oxalate, uric acid, triple phosphate, calcium phosphate and amorphous phosphate, or urates. Their precipitation is caused by transient supersaturation of the urine, the ingestion of food rich in these minerals, or by changes in urine temperature and/or $\mathrm{pH}^{[1]}$.

In a minority of cases, crystalluria is associated with pathological conditions (urolithiasis, acute uric acid nephropathy, ethylene glycol poisoning or hypereosinophilic syndrome) or caused by drugs such as sulphadiazine, acyclovir, triamterene, piridoxilate or primidone, which can crystallize within the tubular lumina and cause renal damage ${ }^{[1,2]}$. Amoxicillin is excreted by the kidneys: $90 \%$ by the proximal tubules and $10 \%$ by glomerular filtration, Amoxicillin crystalluria can cause haematuria and acute renal failure due to tubular damage and medullary congestion $^{[3,4]}$. Its incidence remains unknown ${ }^{[5]}$. 


\section{CASE PRESENTATION}

An 87-year-old female was admitted to our hospital with the following symptoms: fever (maximum temperature: $38.2^{\circ} \mathrm{C}$ ), swelling, pruritus and burning of the right lower limb associated with an acute confusional state. After examination, a diagnosis of erysipelas and acute confusional state (triggered by the onset infection) was made. The patient had a previous history of hypertension, chronic venous insufficiency and dyslipidaemia, with chronic medication that consisted of hydrochlorothiazide (25 mg/day) and simvastatin (20 mg/day). At admission renal function was normal according to her age (GFR: $77 \mathrm{ml} / \mathrm{min} / 1.73 \mathrm{~m}^{2}$ ) as was the urine sample with a pH of 6.5. Treatment with intravenous amoxicillin (1,000 mg) plus clavulanic acid (200 mg) three times per day was initiated. Her therapeutic regimen while hospitalized consisted of these antibiotics together with furosemide (40 mg/day), lorazepam (1 mg/day) and simvastatin (20 mg/day).

On the fourth day of treatment, the patient developed hypogastric pain and decreased urinary output, so a urine sample was taken. Macroscopically, the urine sample was normal, and the sediment contained erythrocytes (5.1 per hpf) and some leukocytes (68.1 per hpf), had a pH of 5.6 and a relative density of 1.005 and, after centrifugation, showed hyaline casts, squamous cells and massive crystalluria. Microscopically, the crystals had the appearance of isolated thin and colourless needle-shaped aggregates with random distribution and were highly birefringent under polarized light microscopy (different from the more commonly observed crystals of uric acid and calcium oxalate). This appearance is also described as 'shocks of wheats' and 'broom bush-like' crystals and suggests a drug-induced crystalluria, which in this clinical context was compatible with an amoxicillin-related crystalluria.

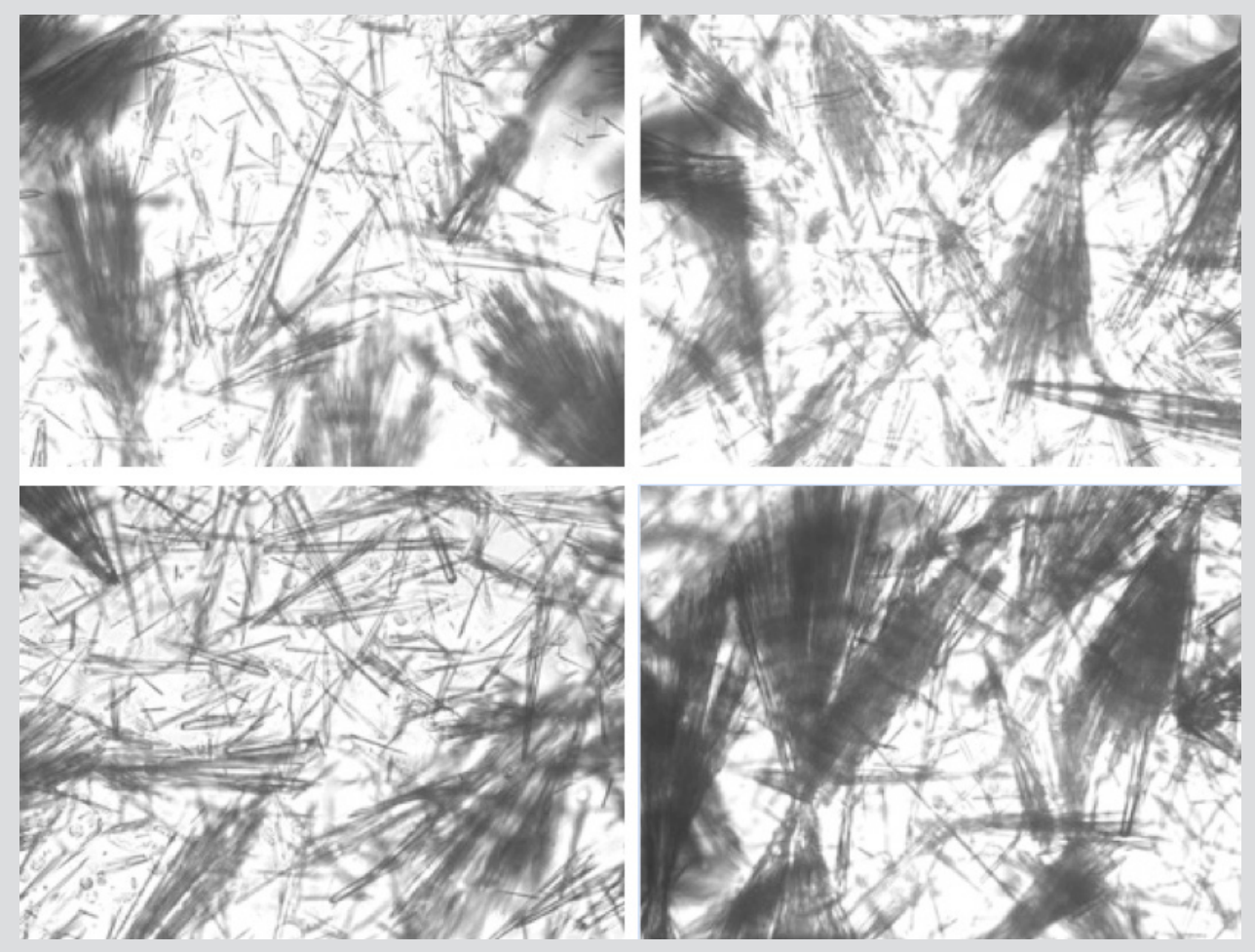

Figure 1. Amoxicillin crystals: large aggregated needle-shaped, 'shocks of wheat' and 'broom bush-like' crystals birefringent under polarized light microscopy

In addition, impairment in renal function was noted (TGF: $59 \mathrm{ml} / \mathrm{min} / 1.73 \mathrm{~m}^{2}$; GRF at admission of $77 \mathrm{ml} / \mathrm{min} / 1.73 \mathrm{~m}{ }^{2}$ ). After amoxicillin/ clavulanic acid was replaced with cefazolin, a new urine sample was collected (after $36 \mathrm{~h}$ ) which showed normal sediment and absence of crystals on microscopy. 


\section{DISCUSSION}

Amoxycillin crystalluria was first described in 1985 in a 26-year-old healthy volunteer, to whom $3.0 \mathrm{~g}$ of amoxicillin was administered intravenously over $20 \mathrm{~min}$ to investigate amoxicillin renal excretion ${ }^{[4,6]}$. Amoxicillin urinary oversaturation (high dosage, short half-life, predominant urinary excretion), insufficient hydration and low urinary $\mathrm{pH}$ favour crystalluria. After amoxicillin is discontinued, crystalluria disappears in 3-24 h, while gross haematuria resolves in 1-3 days and acute renal failure in 3-17 days. Renal failure can be non-oliguric or oligoanuric, and temporary dialysis is rarely necessary ${ }^{[2]}$.

In the described case, our patient presented with a reversible amoxicillin crystalluria, without macroscopic haematuria and low urinary pH. The renal impairment (GFR: $77-59 \mathrm{ml} / \mathrm{min} / 1.73 \mathrm{~m}^{2}$ ) was probably due to the association of massive amoxicillin crystalluria and dehydration. The crystals were not analyzed because the appearance and the clinical context were diagnostic.

The authors have emphasized this complication of amoxicillin use because high intravenous doses are frequently prescribed and some preventative measures such as increasing fluid intake and urine alkalinization can be adopted, especially in individuals with poor selfhydration capacity such our geriatric patient who showed a concomitant acute confusional state. Amoxycillin crystals differ strikingly from the more common urinary crystals, and this along with the clinical information, should lead to the diagnosis with a subsequent reduction in dose or withdrawal of the drug.

\section{REFERENCES}

1. Fogazzi GB. Crystalluria: a neglected aspect of urinary sediment analysis. Nephrol Dial Transplant 1996;11:379-387.

2. Fogazzi GB, Cantù M, Saglimbini L, Daudon MA. A rare but possible cause of crystalluria. Nephrol Dial Transplant 2003;18:212-214.

3. Jones P, Gaber L, Nilsson GR, et al. Acute renal failure following amoxycillin overdose. Clin Pediatr 1993;32:735-739.

4. Sjovall J, Westerlund D, Alvan G. Renal excretion of intravenously infused amoxycillin and ampicillin. Br J Clin Pharmacol 1985;19:191-201.

5. Hentzien M, Lambert D, Limelette A, N'Guyen Y, Robbins A, Lebrun D, et al. Macroscopic amoxicillin crystalluria. Lancet 2015;385(9984):2296.

6. Van Noord C, Wulkan RW, van den Dorpel MA. Crystalluria. Neth J Med 2012;70:84, 87. 